\title{
Analysis of the concepts of building microgrids containing distributed generation objects
}

\author{
Alexander V. Vinogradov ${ }^{1,}{ }^{*}$, Anatoly $Y$. Seyfullin ${ }^{1}$, Alina $V$. Vinogradova ${ }^{1}$, Vadim E. Bolshev ${ }^{1}$, Alexey V. Bukreev ${ }^{1}$, and \\ Zumeyra M. Shakurova ${ }^{2}$
}

${ }^{1}$ Federal Scientific Agroengineering Center VIM, 109428 1st Institutsky proezd 5, Moscow, Russia

${ }^{2}$ Kazan State Power Engineering University, 420066 Krasnoselskaya St. 51, Kazan, Russia

\begin{abstract}
In this article, the authors consider the materials of research on the construction and operation of intelligent power supply systems with a nominal voltage of up to $1000 \mathrm{~V}$, containing distributed generation facilities. The author's approach to the construction of microgrids based on multi-contact switching systems is proposed. The similarities and differences of the presented concepts are determined. The main problematic issues that arise in the process of implementing projects for the construction of microgrids and the management of electric power modes of operation are formulated. The ways of solving the problems related to the management of the modes of operation of microgrids are proposed.
\end{abstract}

\section{Introduction}

One of the most promising areas of modernization of grids of the lowest class of rated voltage up to $1000 \mathrm{~V}$ is the construction of intelligent active-adaptive electrical networks-microgrids. Microgrid networks are low-class grids of rated voltage up to $1000 \mathrm{~V}(\mathrm{LV})$ with distributed generation sources (DG) based on renewable energy sources (RES), storage devices, controlled load, which acts as a single object in relation to the external grid [1]. The idea of creating microgrids was formulated in the first half of the 2000s [2], however, the stage of implementation and construction of microgrids does not go beyond the scope of the diploma and research papers. This circumstance is caused by a number of reasons, such as the lack of the necessary amount of regulatory legal acts, regulatory and technical documents [3], the relatively small prevalence of generating sources based on renewable energy [4] and electric energy storage devices in power systems [5]. Therefore, implementation mechanisms and tools are not common.

\section{Materials and methods}

Within the framework of this study, the method of system analysis, methods of comparisons and analogies, and expert assessments were used. Let us consider the materials of foreign and domestic developments in the construction of microgrids on the example of implementing projects, or as patented devices.

In this study, the construction of microgrids is considered using the devices:

- IDPR (intelligent power distribution routers) [6],

- EPDS (Electric Power Distribution Station),

- MCS (multi-contact switching systems).

\section{Results and discussion}

\subsection{IDPR (intelligent distribution power routers)}

One of the most popular concepts for building microgrids is "power routers" or "Internet of electricity" [7]. An example of such work is the Spanish project "Smart Rural Grid". The key idea of the project is to build rural electric grids based on the widespread use of the devices of the new generation of intelligent distribution power routers (IDPR) [8]. IDPR is a twolevel hardware and software device. At the hardware level, the IDPR is a power electronics device of the same class of rated voltage with electric receivers, combining the functions of a voltage converter, a harmonic filter, a reactive power compensation device, and an electric energy storage device. At the software level, the IDPR implements the functions of monitoring and regulating the electrical mode, controlling switching devices to change the network topology, managing storage devices and electrical receivers, and communicating with the rest of the IDPR and the virtual power plant VPP (virtual power plant). In Catalonia (Spain), within the framework of this concept, a pilot project was implemented to create an intelligent rural electric network for the existing facilities of the electric distribution networks of the electric grid company "EyPESA".

The intelligent electrical grid was built on a section of the existing dead-end radial power transmission line (PL) of distribution electrical grids with a rated voltage of $5 \mathrm{kV}$ and connected to this PL by $5 \mathrm{kV} / 48 \mathrm{~V}$ transformer substations (TS). Individual electricity consumers were connected to the $48 \mathrm{~V}$ TS low-voltage

\footnotetext{
* Corresponding author: winaleksandr@gmail.com
} 
buses not directly, but via the IDPR. All IDPRs are connected to each other and to the VPP (virtual power plant) by a single telecommunications network. The IDPR has two main modes of operation -master mode and slave mode, the choice of IDPR mode depends on the mode of the external distribution radial grid in relation to the TS $5 \mathrm{kV} 5 \mathrm{kV} / 48 \mathrm{~V}$. In the case when the PL $5 \mathrm{kV}$ is in operation, IDPR operates in the slave mode - during peak generation hours it accumulates electricity from distributed generation sources, and supplies it to its electric receivers during peak load hours, the frequency and voltage on the $48 \mathrm{~V}$ grid is provided by the external mode of the $5 \mathrm{kV}$ grid, IDPR only corrects the power quality parameters by balancing the current in phases, reactive power compensation, filtering harmonic components. In the case of an emergency shutdown of the PL $5 \mathrm{kV}$, one of the IDPR switches to the master mode and switches the grid section to the island mode (isolated mode). In this mode, the master IDPR begins to act as the main power source, and regulates the parameters of the electrical mode of the island by controlling other slave IDPR and distributed generation sources connected to the low-voltage buses TS $5 \mathrm{kV} 5 \mathrm{kV} / 48 \mathrm{~V}$, as well as disconnecting or switching on consumers not connected to the grid via the IDPR, depending on the parameters of the post-accident mode of the grid allocated for isolated operation.

\subsection{Electric power distribution station (EPDS)}

One of the most promising concepts for building microgrids is the development of the Japanese corporation NEC [10]. An example of building such a microgrid is shown in Figure 1.

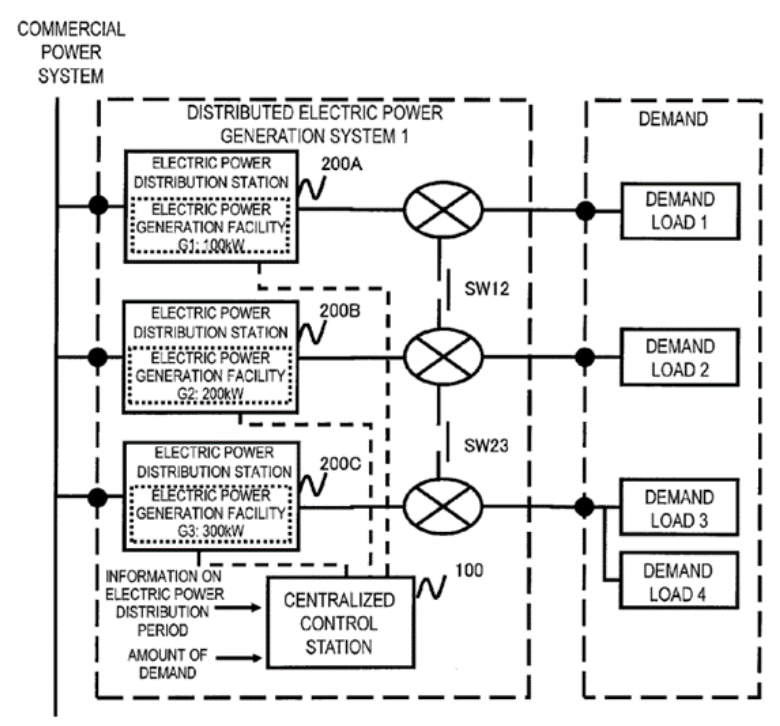

Fig. 1. An example of a microgrid with the use of electric power distribution stations.

This grid consists of five electrical loads of microgrid consumers (demand load 1, 2, 3, 4,5), three distribution power distribution stations (electric power distribution station 200A, 200B, 200C), two internal distribution grid networks (transmission grid networks 300A, 300B), switches (SW12, SW23), a central control station (centralized control station 100). All consumers of such a microgrid are connected to an external (commercial) electrical grid (commercial power system) using distribution stations. Each distribution station includes:

- converter from AC voltage to AC voltage (AC-to$\mathrm{AC}$ converter), or converter from $\mathrm{AC}$ to $\mathrm{DC}$ voltage (AC-to-DC converter), (depending on the type of rated voltage of the consumers of the microgrid),

- generating unit (diesel generator),

- may contain an electrical energy storage device. All power distribution stations have different rated power. Consumers and loads are connected to each other through internal transmission grid networks, while the grid is segmented, each load group is connected to only one distribution power station. This concept has several execution methods with different topologies, which differ in different options for changing its configuration. In the normal mode, the power supply to the consumers of the microgrid is carried out from an external commercial grid, and not from generating electrical installations and storage devices as part of electric power distribution stations.

In case of termination of external power supply at all points of delivery, the power supply of consumers of the microgrid is transferred to the electric power distribution stations. At the same time, the choice of the electric power distribution station from which the power will be supplied will be made in accordance with the algorithm:

- the amount of the required load is determined based on the data of tele-measurements at the time of disconnection, and on the basis of retrospective data for the previous period, which are stored in the database for the same period of time,

- the value of the predicted shutdown period is determined on the basis of retrospective data, on the basis of information from the dispatch center in the event of an emergency mode of consumption restriction, on the basis of manual input by the microgrid operator,

- next, the amount of the required amount of electricity is determined,

- then the most economical composition of the generating equipment (a combination of generating equipment and loads) is selected, which will be able to generate the entire required amount of electricity, depending on the losses during the start of the diesel generator, the economy of the long-term operation of the generator (the power of the diesel installation corresponds to the load value), the loss of electricity in internal communication grids,

- if necessary, the configuration of the microgrid is changed by switching switches (SW12, SW23), the loads and generating equipment are grouped according to the selected most economical composition.

As a result, either all consumers of the microgrid will receive electricity from one most economical generator, or the grid will be segmented into isolated parts, each of which will operate a separate generator for its own load group combined with switches SW12 or SW23. Parallel operation of several electric power distribution station (with the same characteristics) is allowed only within one segment of the microgrid (as part of one electric power distribution station) to supply a specific load (load 


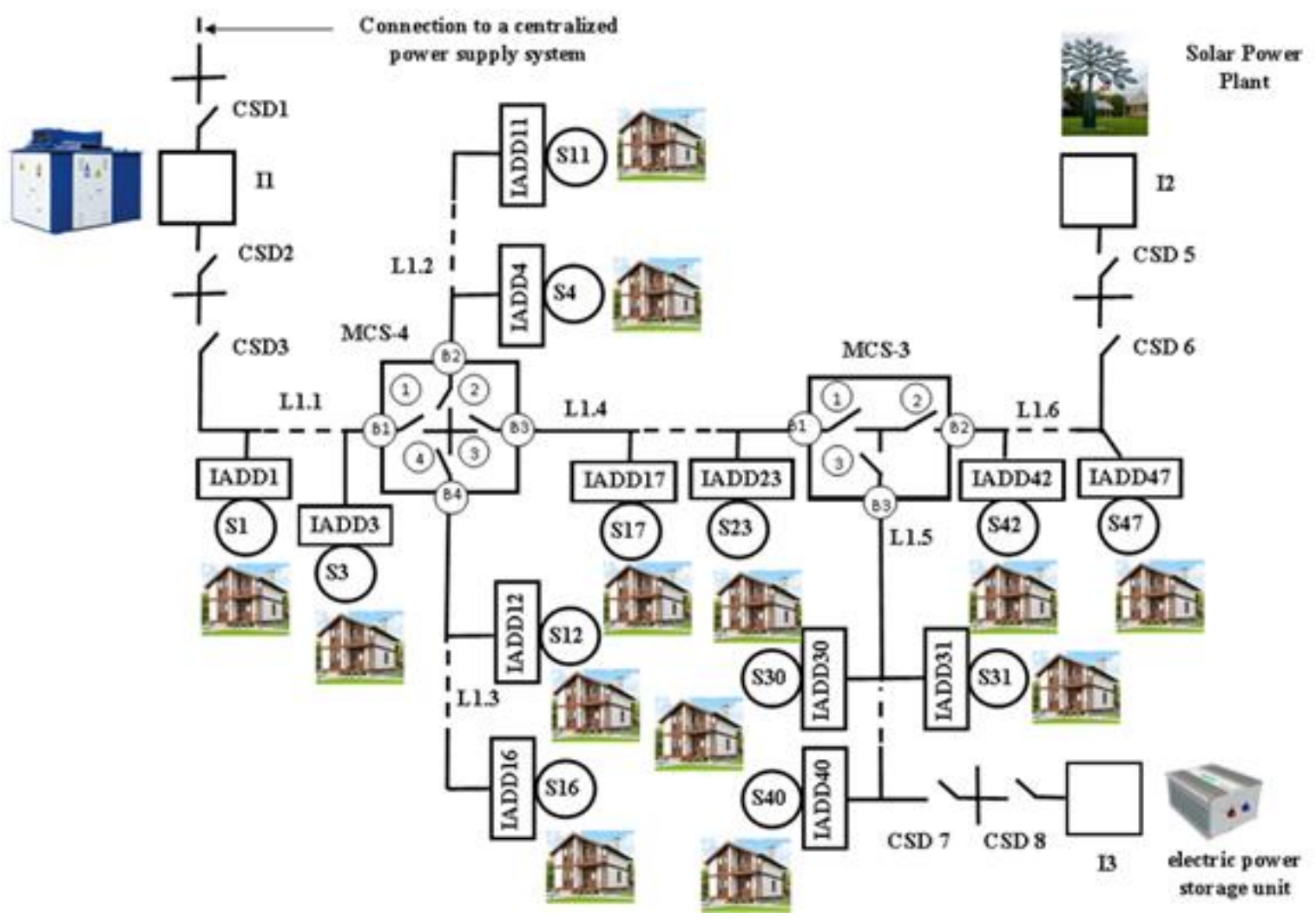

Fig. 2. Diagram of an electrical microgrid with a controlled configuration.

group), while the parallel operation of all electric power distribution stations and loads is not allowed due to the need to develop additional technical measures.

\subsection{MCS (multi-contact switching systems)}

It is possible to effectively solve the problem of building microgrids by using switching devices of a new type of multi-contact switching systems (MCS) $[11,12]$ MCS are switching devices that have 2 or more contact groups, and the contact groups are controlled independently. These devices were developed on the basis of the Laboratory of Power Supply and Heat Supply of the Federal Scientific Agroengineering Center VIM (Moscow, Russia). The use of MCS in electrical grids up to $1000 \mathrm{~V}$ makes it possible to automatically change the grid configuration when the situation changes in it or on the instructions of the operator. Microgrids using MCS can combine different types of sources, as well as contain electric energy storage devices.

Figure 2 shows an example of building a microgrid using MCS. This microgrid contains a solar power plant

$\mathrm{I} 2$, an electric energy storage I 3 and has a connection point to the distribution electrical networks through a transformer substation I3, the sources are connected to the microgrid by the remotely controlled switching device

CSD1-CSD 6. This microgrid contains consumers of electrical energy S1 - S47 and is segmented by two multi-contact switching devices MCS -3, MCS -4 (the numbers in MCS indicate contact groups, the letter B with a number, for example, B1, B2-pin numbers). At the input of all consumers S1 - S47, input-accountingdistribution devices (IADD1 - IADD 47) are installed, providing the possibility of remote and automatic control of them.

To ensure observability, the I1 - I3 sources, as well as MCS-3, MCS-4 and all IADD1-IADD 47s are equipped with sensors of grid operation mode parameters (SGOMP) built into their control units (CU), thereby monitoring the grid operation mode at the point of their installation. Information from the IADD installed in all MCS, IADD, I1 - I3 is transmitted via communication channels to the virtual power plant, which is a grid control unit (GCU) that processes incoming information and generates control commands based on it for the corresponding equipment installed in the grid. Also, information from the SGOMP is transmitted to the grid manager, who can block the operation of the GCU, or adjust the control commands developed by it, transfer the network to manual control.

Figure 3 shows a block diagram of the electrical grid configuration control shown in Figure 2. This scheme implements the principle of grid controllability, that is, at any time, the equipment installed in the grid can be given a command to regulate a particular parameter, for example, a command to the power supply source to change the value of the voltage output to the grid, or a command to make switches, for example, disconnecting one and switching on another contact group MCS-4. 


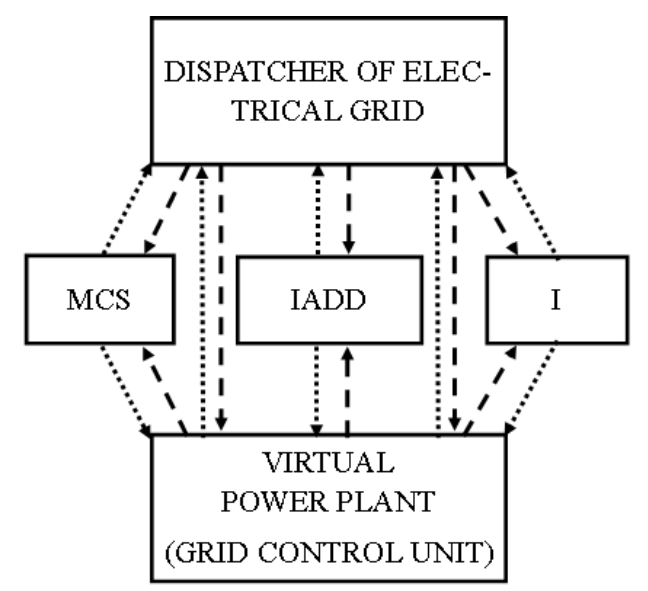

$\ldots . . . \rightarrow$ information about electrical grid operation mode
$\ldots-\longrightarrow \quad$ operation command

Fig. 3. Diagram of an electrical microgrid with a controlled configuration.

The principle of equipment intellectualization is realized due to the fact that the algorithms of the equipment operation contain elements of artificial intelligence that allow it to function with optimal parameters. In particular, they allow you to perform automation and control functions in the absence of communication with the GCU and the dispatcher via communication channels for any reason. In this case, the equipment, for example, MCS, switches to an autonomous mode of operation and its switching is carried out based on the values of the parameters of the network operating modes controlled by the SGOMP built into this equipment.

Application of the CSD scheme, MCS allows you to provide grid configuration flexibility. Suppose that the normal mode is the mode in which the power supply of consumers S1-S23 is from I1, and the power supply of consumers S24-S47 is from I2. In this case, all contact groups MCS -4 are closed, contact group $1 \mathrm{MCS}-3$ is open, and contact groups 2, $3 \mathrm{MCS}-3$ are closed. The power line (L-1), formed by sections L1. 1-L1. 4, is powered by $\mathrm{I} 1$, and L-2, is formed by sections L1. 5-L1. 6. switching MCS contact groups, as well as switching CSD, allows you to form PL from different parts of the grid, transfer power lines from different sources, providing flexibility in grid configuration. Due to the flexibility of the configuration, the principle of segmentation of the grid is also fulfilled, that is, the possibility of dividing it into autonomous segments ("islands"). The principle of integration into the economy is fulfilled by equipping IADD, MCS, I1, I1, I1 with smart electricity metering capabilities. In particular, IADD allows you to perform a step-by-step shutdown of the consumer's load when the specified level of power consumption is exceeded, and this device can provide functions for adjusting the cost of electricity depending on its quality. That is, if the quality of electricity is distorted due to the fault of the energy supply organization, the cost of electricity automatically decreases for the consumer, and if the quality is distorted due to the fault of the consumer, it increases. Similarly, the mechanism for adjusting the cost of electricity depending on the reliability of the power supply is implemented. Methods of adjustment and coefficients of increasing and decreasing the cost of electricity are proposed in the articles $[13,14]$. In addition, it is advisable to use special systems, such as a distributed system for regulating the quality of electricity for threephase four-wire low-voltage grids, to maintain the parameters of the quality of electrical energy of the microgrid within acceptable limits [15].

Table 1 shows a comparison of some of the functional characteristics of microgrids based on IDPR, EPDS, and MCS. It should be noted that each of the concepts is based on the use of a new type of technical device, thanks to the use of which certain functional properties of the microgrid are achieved.

Table 1. Comparison of functional characteristics of microgrids.

\begin{tabular}{|c|c|c|c|}
\hline $\begin{array}{c}\text { Functional } \\
\text { characteristics of } \\
\text { microgrid networks }\end{array}$ & $\begin{array}{c}\text { IDPR } \\
\text { intellige } \\
\text { nt } \\
\text { distribut } \\
\text { ion } \\
\text { power } \\
\text { routers }\end{array}$ & $\begin{array}{c}\text { EPDS } \\
\text { Electric } \\
\text { Power } \\
\text { Distributi } \\
\text { on } \\
\text { Stations }\end{array}$ & $\begin{array}{c}\text { MCS } \\
\text { multi- } \\
\text { contact } \\
\text { switchin } \\
\text { g } \\
\text { systems }\end{array}$ \\
\hline $\begin{array}{l}\text { Isolated mode of operation } \\
\text { of microgrid generators } \\
\text { relative to the external grid }\end{array}$ & Yes & Yes & Yes \\
\hline $\begin{array}{l}\text { Parallel mode of microgrid } \\
\text { generators relative to the } \\
\text { external grid }\end{array}$ & Yes & No & Yes \\
\hline $\begin{array}{l}\text { Application of electric } \\
\text { energy storage devices }\end{array}$ & Yes & Yes & Yes \\
\hline $\begin{array}{l}\text { Segmentability of the } \\
\text { internal configuration of } \\
\text { the LV microgrid }\end{array}$ & No & Yes & Yes \\
\hline $\begin{array}{l}\text { Ability to group } \\
\text { consumers }\end{array}$ & No & Yes & Yes \\
\hline $\begin{array}{l}\text { The ability to operate } \\
\text { generators of various types }\end{array}$ & Yes & No & Yes \\
\hline $\begin{array}{l}\text { Connecting generators and } \\
\text { the external electrical grid } \\
\text { via power electronics } \\
\text { devices }\end{array}$ & Yes & Yes & No \\
\hline $\begin{array}{l}\text { The ability to adjust the } \\
\text { parameters of the quality } \\
\text { of electrical energy }\end{array}$ & Yes & No & Yes \\
\hline $\begin{array}{l}\text { Central operating mode } \\
\text { control device (Virtual } \\
\text { Power Plant) }\end{array}$ & Yes & Yes & Yes \\
\hline $\begin{array}{l}\text { Ability to work without a } \\
\text { central mode control } \\
\text { device }\end{array}$ & Yes & No & Yes \\
\hline $\begin{array}{l}\text { Localization of damage } \\
\text { within the microgrid }\end{array}$ & Yes & Yes & Yes \\
\hline $\begin{array}{l}\text { Devices for monitoring the } \\
\text { state of microgrid } \\
\text { equipment, operating } \\
\text { mode, and commercial } \\
\text { electricity metering }\end{array}$ & Yes & Yes & Yes \\
\hline $\begin{array}{l}\text { Competitive selection of } \\
\text { geneticizing installations } \\
\text { by economic indicators }\end{array}$ & No & Yes & No \\
\hline
\end{tabular}

The common similarity of all three concepts is:

- the need to use electric energy storage devices,

- wide application of devices for remote control of switching devices and monitoring of electrical mode parameters, 
- centralized control of electrical modes,

- telecommunications network microgrid [16].

The main differences are

- in various approaches to the use of power electronics devices,

- in various ways of parallel operation with the external electrical grid,

- in various ways to manage the internal configuration of the grid,

- in various means and methods of controlling the parameters of the electrical mode and the quality of electrical energy.

\section{Conclusions}

All three concepts considered are suitable for building microgrids, each of them has advantages. The efficiency of these microgrids and the reliability of power supply to consumers will primarily depend on the quality of design solutions, and on the effectiveness of managing operating modes during operation. However, for the effective application of a particular concept, it is necessary to solve the following problems:

- at the design stage, a comprehensive analysis of the loads of the designed microgrid is required (their geographical location, the category of power supply reliability, the characteristics of electric receivers, etc.),

- based on a comprehensive load analysis, the optimal composition of the generating equipment and microgrid storage devices is selected,

- development of an optimal microgrid scheme that will provide the required reliability and efficiency indicators,

- development of a telecommunications network that provides control of microgrid equipment using a centralized control device, interconnection with the dispatch center of the external electrical grid,

- development of technical means for controlling electrical modes and parameters of electrical energy quality (such as automatic synchronization devices, local devices for automatic frequency reduction(increase) limitation, local devices for automatic voltage reduction(increase) limitation),

- development of relay protection and automation devices capable of changing the settings in accordance with the change in the configuration of the microgrid [17],

- development of algorithms and methods for optimizing the production, storage and consumption of electric energy.

\section{References}

1. Thakar S.1, Vijay A.S.1, Doolla S. 2019 System reconfiguration in microgrids sustainable Energy, grids and networks 17100191

2. Meyer J., Peedin J. 2003 A microgrid worth 'bragging' about Power engineering 107(5) 48

3. Vinogradov A.V., Seyfullin A.Y. 2021 Analysis of regulatory documents on the creation and operation of intelligent power supply systems for rural consumers Elektrotekhnologii I elektrooborudovanie v APK 1 (42) 8-15

4. Vinogradov A.V., Seyfullin A.Y. 2020 Promising energy sources for microgrids of rural power supply systems Agricultural Engineering 4 (98) 4654

5. Vinogradov A.V., Seyfullin A. Y. 2020 Analysis of the concepts of building power supply systems for rural consumers containing several sources of electricity. Vestnik NGIE'I 2 (105)32-44

6. Xiangying X., Leyi G., Yang L. 2019 Chinese Energy Internet Construction Promotes Development of Distributed Renewable Energy Mini Grid. IOP Conference Series: Earth and Environmental Science 252 032190. DOI: 10.1088/1755-1315/252/3/032190

7. 7. Harmon E., Ozgur U., Cintuglu M., Azevedo R., Akkaya K, Mohammed O. 2018The Internet of Microgrids: A Cloud Based Framework for WideArea Networked Microgrids. IEEE transactions on industrial informatics 14(3) 10.1109/TII.2017.2785317

8. Buehner V., Franz P., Hanson J., Gallart R., Martinez S., Sumper A., Girbau-Llistuella F. 2016 Smart grids for rural conditions and e-mobility applying power routers, batteries and virtual power plants. Cigre 2016. F-75008 PARIS C6-308. 1-10

9. Smart grids for rural conditions and e-mobility Applying power routers, batteries and virtual power plants from https://upcommons.upc.edu/bitstream/handle/2117/9 8927/C6308.pdf? sequence $=1$ \&isAllowed $=y$

10. Yumi T., 2015 Distributed electric power generation system, control station, and method of controlling the same. Patent No. US 20150318698A1 USA, declared 9.06.2015; publ. 5.11.2015

11. Vinogradov A. V. 2019 Types of multi-contact switching systems. Agrotexnika I e’nergoobespechenie. 2 (23) 12-26

12. Vinogradov A.V. 2019 Concept of building intelligent electrical networks based on the use of multi-contact switching systems. Topical issues of energy in the agro-industrial complex. Proc. Int. Conf In: all-Russian scientific and practical conference with international participation (27 Feb. 2019), Blagoveshchensk. 109-115

13. Borodin M. V. 2013 The principle of Correction of the cost of consumed electricity depending on its quality. Naukovij visnik NUBiP Ukraïni. Seriya: Texnika ta energetika APK. 184(1) 165-171

14. A.V. Vinogradov, V. E. Bolshev, A.V. Vinogradova, M. V. Borodin, A.V. Bukreev. 2019 Technical and economic ways to improve the efficiency of power supply systems for rural consumers. Vestnik agrarnoj nauki Dona 3 (47) 5967 
15. Dovgun V., Temerbaev S., Chernyshov M., Novikov V., Boyarskaya N., Gracheva E., 2020 Distributed power quality conditioning system for three-phase four-wire low voltage networks, Energies 13(18) 4915, DOI: 10.3390/en13184915

16. Kim J-S, So S., Kim J.-T., Cho J.-W., Park H.-J., Jufri F., Jung J. 2019 Microgrids platform: A design and implementation of common platform for seamless microgrids operation Electric Power

Systems Research 167 21-38. DOI: 10.1016/j.epsr.2018.10.019

17. Kulikov A.P., Sharygin M.V., Ilyushin P.V. 2020 Principles of organization of relay protection in microgrids with distributed power generation sources. Power technology and engineering 5(53) 611-617 DOI: 10.1007/s10749-020-01125. 